\title{
A Review of Innovation and Change Management: Stage Model and Power Influences
}

\author{
Luca Bucciarelli
}

York St. John University, Business School, Lord Mayor's Walk, York YO31 7EX, UK

Copyright (c) 2015 Horizon Research Publishing All rights reserved.

\begin{abstract}
This work is presenting the main theories on organisational behaviour when facing change and innovation management. The change process is necessary in order to maximise the innovations and/or to adapt to new realities [1], leadership and consequently management are critical factors to drive the change itself [2]. The first part of this work is a literature review of the main models for leading innovation and change. The most relevant theories and application to the organisational management are taken in account and critically analysed. It is followed by the exploration of a case study of an unsuccessful change and how to transform it into a successful one.
\end{abstract}

Keywords Leadership, Change Management, Innovation, Higher Education

\section{Introduction}

The present time sees the opening of international markets, the facilitated access to information and the relatively high level of freedom in transportation and mobility of individuals, goods, services and know-how. Organisations are facing a new approach to the globalised world that involves a larger and theoretically infinite amount of competition and hazards. A time of global prospective with opportunities open to many more factors, where organisations are not immune from technological, financial and cultural forces driven by the present economical system. Changes are a constant issue in contemporary organisations, that, by driving an innovating approach to novelty can navigate their success. Innovation represents the introduction of new things and the way of doing them to generally bring benefit. It can relate to the fields of: markets, systems, production of goods and services, processes, but also cultural behaviour, organisational structures and their management.

\section{A Review of Theories on Innovation}

Innovation is the introduction of new and improved ways of doing things [3] as well as the successful contribution that new ideas can have on organisations and social environments [4]. It refers to serveral aspects into the organisational space. As an initial definition we can take the 4Ps model that takes into account innovation in terms of product (what we do), process, (how we do), position (who we do for) and paradigm (how we frame) [5]. Sometimes the borders among these aspects are blurred as the same innovation might imply two or more of the elements in the 4Ps model. For example in services often a new service might imply both a new product and a new process. It is also true that strategic decision taken by the organization in order to introduce innovation imply cultural, functional, technical aspects as well as resources and other external dynamics (eg: customer engagement). Therefore innovation does not involve a single area of organisational management, as describe in the prospective proposed by Goffin and Mitchell [6] who represent it with a pentathlon analogy. In the past, the innovation process was often compared to a marathon, metaphorically imaged as a run from one place to another. In their prospective the disciplines under which the innovation and change performance should be taking place are multiple, at least five: Ideas and creativity, priorisation and selection, implementation, strategy of innovation, people and organisation. Each of these essential elements represents a complex and challenging area competing simultaneously in the innovation process. Innovation is also seen as radical or incremental, Balogun and Hailey [7] analyse in depth the quantitative prospective where innovation can be seen as incremental: when the process impact partially and is characterized by a proportional growth, in other words the organisations keep doing what is usual, but in a potentially more efficient and effective way. Innovation is radical or "Big Bang" when they are revolutionary and imply the organisation to work on something new and different.

Regarding the timing, innovation can be considered either as relative, where the innovative component is already in place - perhaps in other organisations - but is completely new for the one introducing it, or as an absolute novelty: an invention [8].

Not all inventions turn into innovation since the inventing process is not always an active one, indeed, inventions need 
to be taken into account by an innovation process in order to produce effects [8]. All innovations imply a certain level of change while it is not true of the opposite, in-fact there can be a change because of factors that does not necessarily imply an innovation. Creativity is a critical contributor to innovation, more often present in creative environments where supervisors encourage the member of the organisation to creativity, contributes with values, guarantee sufficient resources and freedom [9].

Teresa Amabile (1997) draws a concept of individual creativity as a merge of: expertise, creative skills and the motivation one has to achieve a task. To guarantee a fertile ground for innovation and creativity in an organisation, there has to be appropriate resources in order to give the tools and avoid an excessive workload. Practice of organisational management should be supportive of work groups and assigning challenging tasks, management should be encouraging through the supervisors and motivating the organisation members towards goal achievement [9].

\section{Change Management for Innovation}

Change represents a transformation or a realignment of the existing assets in an organisation. Innovation and change are connected by a strong cause-effect relationships, change effects are in fact triggered by strategic action either structural, functional or conditioned by external factor which imply transforming or realigning some (or all) organizational assets. It can be seen in various scales and definition, sometimes open to a large level of uncertainty to define when one category becomes the other or vice-versa. In a scale of end result and/or nature, change (as well as innovation) can be defined as incremental or revolutionary [7] and lead to four different types: adaptation, reconstruction, evolution and revolution.

Concerning the timing of the change, it can be seen as: anticipatory or proactive versus reactive [10]. It is anticipatory when the change is taking place before a reality is appearing on the organisations life, while it is reactive when the change follows an event suggesting/obliging to transform or realign. This definition is not a clear statement, perhaps a change can be seen as anticipatory while indeed is following a sign of something about to happen. There are obviously changes that are clearly either anticipatory or reactive, but this definition opens a large scale of uncertainty in defining when one category becomes the other or vice-versa. Something similar happens with the definition of hard change and soft change [11] where the hard change has a positivist approach that often relates to technical matters or data more easily quantifiable, while soft changes often deal with organisational culture, process and practices, a negotiation of management and meanings. Changes, as defined by Senior and Fleming (2006) are often characterized by a "soft complexity" which implies a need for redesigning systems at many levels of the organisation.

\section{Leading Innovation and Change}

Change is an outcome effect of innovation that is often planned complementarily to the introduction of the innovation itself. An effective and efficient innovation and change management involves support, by getting the people on the side of the change. Before and during every change, there is a need to analyse the key issues and interest but also what kind of issues are due to a different stakeholder. The power of a stakeholder is not proportional with his control over a change and/or the organisation in general, in fact the influence might be very large but the control might be reduced to a smaller range of action in comparison to organisational environment [12]. Among the many studies on innovation management leading to change, the stage models are much discussed but yet the most common study and analysis. Change is not certainly a process which can be easily achieved through a steps and stage recipe, nor is it a process characterised by a fix degree of linearity [7].

Lewin [13] synthesis the innovation and change theory in three necessary steps:

1. Unfreezing the organisation, getting rid of the attitude that individuals have against the change, creating a vision of a better future by delivering information and establishing the urgency to change.

2. Shaping, moving through the change process by getting the people engaged, creating equilibrium among the driving and restraining forces inside the organisation

3. Refreezing: creating and maintaining a new condition.

Hayes' theory recognizes the need to implement the three steps of change into a model with five stages [13]:

1. Recognizing the need for change and starting the process by analysing the reason and need for change.

2. Diagnosis by reviewing the actual state and designing a possible future, creating the urgency and the expectation on the members of the organisation.

3. Preparing and planning for implementation by creating the timing, the management plan and the team of leading members.

4. Implementing and reviewing by taking the steps to lead to the change and review the outcomes.

5. Sustaining, which can be seen as the refreezing model of Lewin where the new behaviours are established among the organisation member.

The most popular study on leading change is Kotter's eight-stage model [14]. Kotter started from the observation of failure in change and creates a sort of positive engineering vision to transform the error into stages to possibly follow for a successful change:

1. Establish a sense of urgency by examining the reality, possible crisis and/or opportunity.

2. Creating the guiding coalition of leaders and managers who will work in team with the rest of the members of the organisation and the change agents.

3. Developing a vision and strategy to direct the change 
and achieve the goal.

4. Communicate the change vision with every means in a constant mode. Not only by emails, by flyers but by really acting in a way that communicate a different symbol

5. Empower and act according to the vision by surpassing eventual obstacle, encouraging creativity and risk taking.

6. Create visible short-term wins and allow a reward for those who drive the change. There is a sort of learning process involved which makes the organisation able to update and by learning from the change driving it itself.

7. Consolidating gains and builds new changes prospective by promoting and encouraging the people as well as making credible the new systems and practice.

8. Institutionalise the new approaches, develop the leadership and a more effective management.

Organisational change is a very fluid process affecting several components to be strategically maneuvered instead of solely following a stage/step approach. In addition, not all the stages are consequential, in fact, from one you can go back and reinforce the previous or vice versa. On another note you can also consider not all stages are present in a process of change nor all of them need the same attention and intensity. Each change is different, it is not always true that following a stage/step model will lead to a successful result. As Kotter [2] affirms, changes are messy and surely filled with surprises along their journey. A critique of Kotter's model is that he does not take into enough consideration the first stage of Haye's model where the need of change is taken into analysis. It is also true that often time a need of change cannot easily be seen, perhaps, because the way things are, is perceived as a successful way, or, because the performances are not monitored sufficiently effectively. Surprises and failures often happen when organisations try to innovate, when they change to something new, on the other hand it is also affirmed by Sutton and Pfeffer [15] there is nothing more dangerous than not changing in organisations. Sutton and Pfeffer instead of rushing through the change, invite to pose eight questions about it that are certainly useful. Is the case, is the change necessary and is it going to be better than now after the change? Is the time, effort and costs worth the process? What really change and who/what is getting beneficial effect? Do you have enough power (resources, allies, etc) to make the change happen? Are there too many changes so that people become confused and/or the energies are splitted among the different processes? Is it possible to stop the change in case is necessary? It is debateable the stage model approach: very managerial, considered too analytic and probably too positivist about the change process - while the soft/people factor (resistance and opposition) is the one that often imply a failure. Another critique generally brought to the stages model, and in particular to Kotter's one, is that it really focuses on leadership as the most important aspect of the change process without taking enough in consideration the economical and financial aspect; the political forces, both inside and outside the organisation; the oppositions and the other restraining factors to change. The stage model approach is somehow too linear and prescriptive, so perhaps, an alternative model to the change process can be seen, instead of a sum of steps/stages as a set of activities that a leader for change needs to accomplish. Buchanan and Boddy [16] suggest that a leader should be able to: understand and manage the details of the change, control and plan the change managerial and operational aspect, deal with the people in the organisation who are driving and are driven by the process of change.

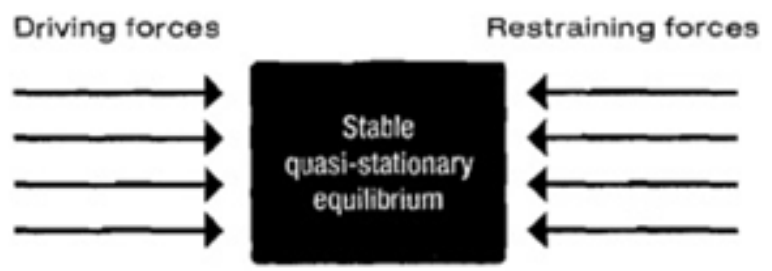

Figure 1. Source: Hayes, J., 2010. The Theory and Practice of change management, 3rd ed. Palgrave, New York. P.43

Supportive and resisting factors and forces should be observed both at the beginning and during the process. Lewin's [12] Force Field Analysis theory (Fig.1) is a useful, yet not too analytic, tool to describe the tensions between the driving and restraining forces to a change. With a qualitative method it shows on one side the driving agents/factors and their power in pushing toward the change process, on the other, the restraining forces working on a contrary effect.

During the 1980's political skills and power influence were seen as essential for leaders, innovation and change agents [18]. Politics is about winning support [19] and can be done through tactics and tools. Power influence, politics as well as leadership is mostly about influencing through persuasion, inspiration, appeal, exchange, collaboration, ingratiation, individual and collective pressure both because of an institutional role or leadership skills [20]

\section{Materials and Methods}

The presented case study case study is based on a Higher Education Institution in Italy nominated from now on " $\mathrm{X}$ " which is hosting mostly study abroad students who study at $\mathrm{X}$ for one semester/year but are degree-seekers in other Universities. The data collection has been performed mainly through direct observation and long interviews with ethosociologiocal research method. The represented level of resistance to change is applying the Force Field Analysis through-out the several steps of change in order to allow a visible quantification of forces. The case presented (opening of new schools) involves several changes in the organisation asset but in particular I will be referring to the marketing and communication department that counts many stakeholders in and around the organisation as represented in the graphic 
map below (Fig. 2). During the past five years, $X$ has seen an extremely rapid growth both in terms of enrolment as well as in its curriculum offering. In the biannual 2009-2011, X developed seven new divisions offering new fields of study and therefore has also created seven new schools, each of which was given a new name.

\section{Unsuccessful Change}

Following the establishment of the new divisions and schools, a relevant reactive [10] change to the marketing strategy took place and a number of new, and separate, brochures (one for each school and more) had been made in order to market the new assets of $\mathrm{X}$. This marketing/communication process created a deep confusion among the clients and partners Universities that previously sent students to study at $\mathrm{X}$ as well as to the newly marketed schools. The new brochures were not communicating the change and increment of $\mathrm{X}$ but seemed more to be promoting a completely new set of institutions. By using Lewin's [12] Force Field Analysis (Fig. 3), it is easy to visualise and define the driving forces of the change in the marketing strategy are mainly focused on the aesthetics of the product, rather than communicating the content and the new vision. The owner and the art director, because of their will to represent the new vision primarily under an aesthetic prospective are pushing for a multitude of brochures, websites, and other visual communication marketing means, enforcing this change with their political power in the organisation. On the other side, partners, clients as well as the Director for University relations and the admission office, are forcing - with a weaker power - toward a more clear approach to facilitate the effectiveness and the understanding of the change.

By analysing this change under the three type of activities to be undertaken by change agents [16] it is noticeable that the details of the change itself are not well understood. The confusion created by the multitude of marketing materials was not taken into account. The directive and coercive leadership style of the most powerful stakeholders made effective the hard component of the change [11] creating the new materials, but left behind the soft aspects related to human and cultural management among the organisation members as well as the rest of the external stakeholders, who did not understood the marketing strategy and therefore were unable to share and communicate the new asset. Both inside the organisation as well as outside to the market, the effect of the change did not bring any benefit but turned instead into a disaster, probably since the fourth step of Kotter's steps theory [14] was not sufficiently taken into account and the new vision was not communicated properly externally, nor internally.

\section{Successful Change}

The Director of University Relations made every effort to establish a sense of urgency [14] on changing the marketing materials into more effective ones, by providing data proving the unsuccessful strategy, sharing the vision and the mission of the proposed change among the stakeholders and the shareholder and fighting against the resisting members of the organisation who had developed multiple brochures strategy. The influence [18] the Director of University Relations had on the organisation's stakeholders drove X's graphic designers team to create a temporary brochure for a fair in which $\mathrm{X}$ was participating.

The temporary brochure clearly stated to the audience the possibility to study at $\mathrm{X}$ and launching the novel prospective of study in the new divisions inside X. It was efficiently communicated that students were going to study at $X$ and had a chance to select a larger number of field of studies. The fairs' success was seen as a short term win [14], the resistance to change was reduced. With an updated (Fig. 4) Force Field Analysis [12] it is evident the forces that before were restraining the effective communication of the change and privileged the organisation's aesthetic image and brand moved to the other side and are now driving toward the commonly shared strategy of the single brochure. The art director remains neutral on the condition of having enough representation and visibility (pictures) in the new materials structure, so did the academic Dean who's pursuing mainly workload stability.

This successful change was mainly driven by a leadership that was able to establish the urgency [14] and recognize the need [13] of a transformation in the marketing strategy.

Most of Kotter's [2] eight steps model have been taken into account - even if partially - to drive this change, in fact: it was first established - especially by the Director of University relations, the Partner Universities and the other clients - a strong sense of urgency ( $1^{\text {st }}$ step), through the examination of the mis-communication created by the multitude of brochures (new reality). This step led to the creation of a guiding coalition ( $2^{\text {nd }}$ step) by influencing the stakeholder and winning the support for the change. With the first trial of a temporary single brochure, the guiding coalition had shared the vision and communicated effectively the new marketing strategy, then, despite the cost of re-creating new materials, it guided the department to a new way to present $X$ 's offering ( $3^{\text {rd }}$ and $4^{\text {th }}$ steps). The change was increased and empowered on every short win, visible over the year especially with the fairs feed-backs $\left(5^{\text {th }}\right.$ and $6^{\text {th }}$ steps). The organisation (already well known and marketed worldwide) was led to a new way of communicating its products, create a new uniformed brochure containing all the information on the divisions and schools born under the existing institution $\mathrm{X}$. The successful change was sustainable and stayed in place for years. The enrolments started to grow and diversify into the new schools and departments created, so that, the gain from this change become institutionalised and applied to other $\left(7^{\text {th }}\right.$ and $8^{\text {th }}$ steps) marketing tools and communication aspects. 


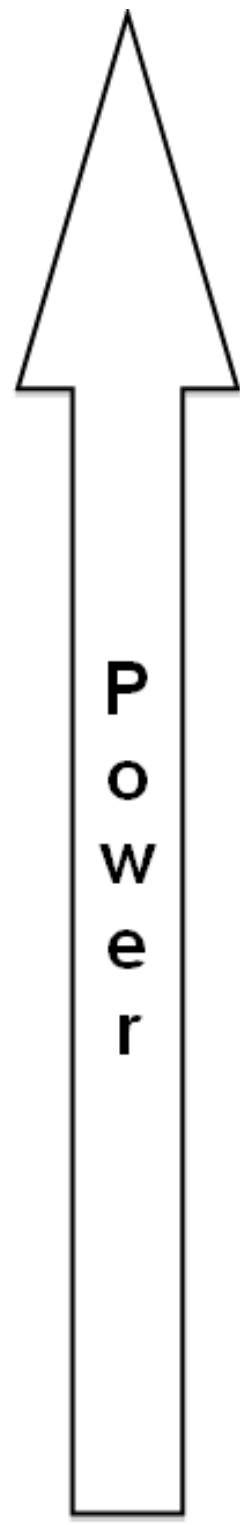

\section{Partners, providers, and} individual clients sending students and faculty at $X$ to fulfil part of the academic curiculum abroad the academic curriculum abroad. academic content, services, eto since theyinmost cases co-share goals and liability matters.

\section{The organisation brand since} fifthteen years has been always image Giventhe quality design organisation (study abroad). X's representation has been always centred on aestheticaspects rather than academic contents; state of the art facilities rather than rigour of courses; romanticimaginaries of abroad experiences rather than curriculum structure.

The organisation owner is
the main shareholder and
the president. The company
is completely owned by this
personwhois also its
founder. The owner has a
background as a designer
and is involved with most of
the aspect of the
organisational management,
in particular the marketing
department she direct and
manage personally.

The Chair of the School of Communication and Publishing is one of the first alumniwho was offered to remain in the organisation and work side by side with the president. She would never express a real opinion but sup port unconditionally the president's decisions.

The graphic designers are a team of two who design brochures, and other marketing materials. One of the two designers is a collaborator of the owner since the organisation was funded, but he is lately considered (by the most powerful stakehol ders) a non creative, obsolete and skillless professional. His role is mainly subsidized by the other emerging leading designerwhois a so the owner's nephew.

The Admission office is the main operational contact forclients and

partners. This office need to sustain all the lacks of communication from the marketing department as it has to drive the

effectiveness, facilitate the enrolments, etc
The Director of University Relations is the main contact for institutional relations with clients and partners. He maintains the portfolio and devel op further relations serving as the spokemission, values and asset.

The Academic Dean has been getting into conflict with leadership because of her lack of initiative and a certain level of resistance to the institutional change which led the organis ation to schools.
The art director is the owner's partner in life. He com own creative objects. He is also a teacher of cligital

photography. Given the lack the findependent publications, pushing to is really pushing to have his photos marketing materials.

Figure 2. A stakeholders map prioritized by power 


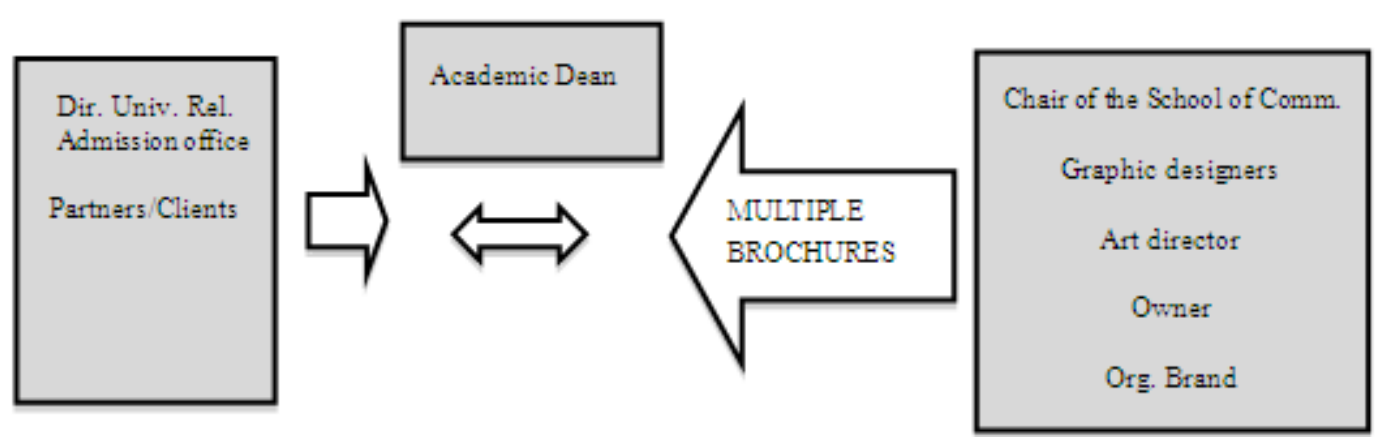

Figure 3. FFA multiple brochures
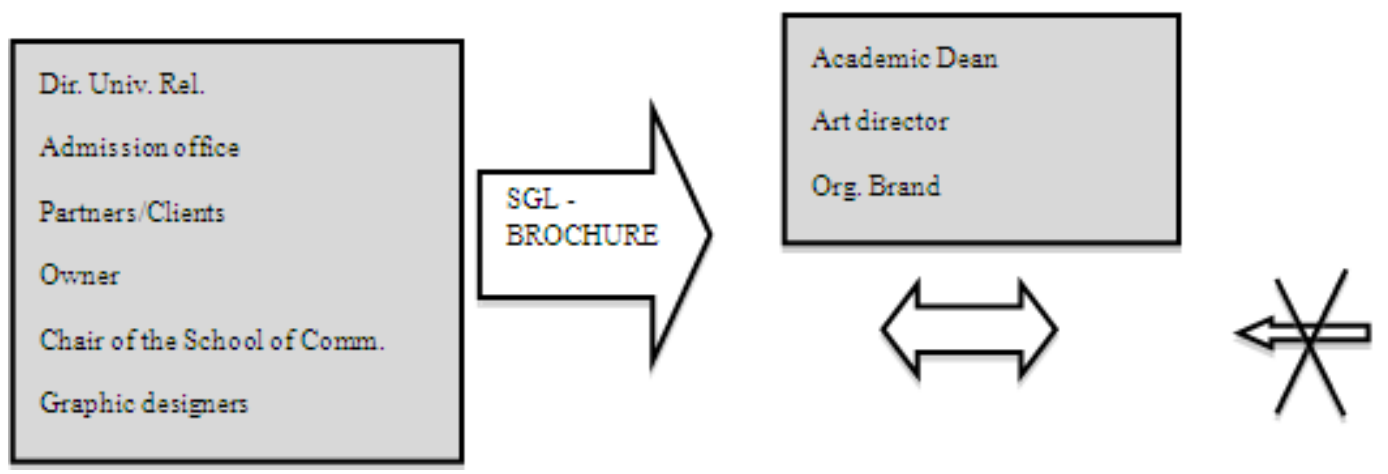

Figure 4. FFA single brochure

\section{Conclusions}

This work aims to review the most important theories of Innovation and Change, compare some of the most managerial ones with the soft people oriented ones. The qualitative approach of the proposed study, take particular attention to the human interaction and the stakeholder's power in the change process. The eight stages proposed by Kotter to facilitate the change implementation are represented during the various stages of the proposed change. The establishment of sense of urgency is noticeable as a crucial point to facilitate change by creating a stronger people engagement. The forces equilibrium has been analysed and represented through the Force Field Analysis diagrams in order to visualise the balance of engagement and power influences toward the change. The proposed change was mostly to realign values and the owner mindset that did not allow a proper change management process because of the misaligned strategy in regards to the corporate goals. Further studies and observation can be developed on the stage model of change and the interaction it has on strategies, stakeholder balances, power, culture and forces equilibrium.

\section{Acknowledgements}

The author would like to thank Rebecca Valpy for the overall support and the proofreading of this work.

\section{REFERENCES}

[1] Beerel AC. Leadership and Change Management. Los Angeles: Sage; 2009.

[2] Kotter JP. Leading Change. Cambridge MA: Harvard Business School Press; 1996.

[3] West M, Borrill C, Dawson J, Brodbeck F, Shapiro D, Haward B. Leadership clarity and team innovation in health care. Leadersh Q. 2003;(14):393-410.

[4] Porter M, Ketels H. UK Competitiveness: Moving to the Next Stage. DTI Econ Pap Rep Ser. 2003;3.

[5] Tidd J, Bessant J. Managing Innovation: Integrating technological, market and organisational change. 4th ed. Chichester: Wiley; 2009.

[6] Goffin K, Mitchell R. Innovation management : strategy and implementation using the pentathlon framework. Basingstoke: Palgrave Macmillan; 2010. 1-40 Ref and Notes: 370-372 p.

[7] Balogun J, Hailey VH. Exploring Strategic Change. London: FT/Prentice Hall; 2004.

[8] Adair J. Leadership for innovation : how to organise team creativity and harvest ideas. Kogan Page; 2007.

[9] Amabile T. Motivating Creativity in Organizations. Calif Manage Rev. 1997;40(1).

[10] Nadler D, Tushman M. Beyond the charismatic leader: leadership and organizational change. Calif Manage Rev. 1990;(32/2):77-97.

[11] Senior B, Fleming J. Organizational Change. 3rd ed. London: FT/Prentice Hall; 2006.

[12] Covey R. The 7 Habits of Highly Effective People - Powerful 
lessons in Personal Change. Simon \& Shuster Inc; 1989.

[13] Lewin K. Field Theory in Social Science. New York: Harper \& Row; 1951.

[14] Hayes J. The Theory and Practice of change management. 3rd ed. New York: Palgrave; 2010.

[15] Kotter JP. Why Transformation Efforts Fail. Harward Bus Rev. 1995;(March-April):pp. 59-67.

[16] Sutton R, Pfeffer J. Hard Facts, Dangerous Half-Truths and Total Nonsense. Cambridge MA: Harvard Business School Press; 2006.
[17] Buchanan D, Boddy D. The expertise of the change agent. London: Prentice Hall; 1992.

[18] Kotter J. Power and Influence. The Free Press; 1985.

[19] Schlesinger L, Kotter JP. Choosing strategies for change. Harv Bus Rev. 1979;(March/April 57/2):106-14.

[20] Yukl G. Leadership in Organizations. New Jersey: Prentice Hall; 2010. 